\title{
Strategies to Improve the Supply of Services in the Nigerian Social Health Insurance Programme: Healthcare Provider Perspective
}

\author{
Obi Ikechukwu Vincent ${ }^{1,}$, , Okoronkwo Ijeoma Lewechi ${ }^{1,2}$, Adi Jesse Ashumate, \\ Iloh Gabriel Uche Paschal ${ }^{4}$, Yakubu Adole Agada-Amade ${ }^{1}$, Ikwudinma Augustine Obiora ${ }^{5}$ \\ ${ }^{1}$ Department of Health Management and Administration, University of Nigeria, Enugu, Nigeria \\ ${ }^{2}$ Department of Nursing Services, University of Nigeria, Enugu, Nigeria \\ ${ }^{3}$ Department of Health Services, Federal University Wukari, Jalingo, Nigeria \\ ${ }^{4}$ Department of Family Medicine, Federal Medical Centre, Umuahia, Nigeria \\ ${ }^{5}$ Department of Family Medicine, Alex Ekwueme Federal University Teaching Hospital, Abakaliki, Nigeria
}

Email address:

ivcobi@yahoo.com (O. I. Vincent)

${ }^{*}$ Corresponding author

\section{To cite this article:}

Obi Ikechukwu Vincent, Okoronkwo Ijeoma Lewechi, Adi Jesse Ashumate, Iloh Gabriel Uche Paschal, Yakubu Adole Agada-Amade, Ikwudinma Augustine Obiora. Strategies to Improve the Supply of Services in the Nigerian Social Health Insurance Programme: Healthcare Provider Perspective. Journal of Public Policy and Administration. Vol. 3, No. 4, 2019, pp. 98-105. doi: 10.11648/j.jppa.20190304.14

Received: November 21, 2019; Accepted: December 13, 2019; Published: December 24, 2019

\begin{abstract}
Introduction: The Nigerian government has introduced various forms of health insurance programme as a means of supplying quality healthcare services to its citizens all in attempt to attain the universal health coverage. Unfortunately, these various forms of Social Health Insurance Programme (SHIP) have witnessed inefficiencies in the supply of healthcare services and this is evidenced by observed adverse selection and supplier induced demands which are major causes of market failure in health insurance industry. Therefore, there is a need to deduce unique strategies to improve supply of health insurance so as to reduce the barest minimum the incidence of market failure which has impacted negatively on the health insurance industry. Methods: The study adopted qualitative approach by using in-depth interviews (IDIs) method. Nine (9) key informants were purposely sampled from three (3) purposively selected hospitals, one from each categorized type of facility. Content analysis was adopted and further analysis was achieved with the aid of Nvivo 11 software, which coded and categorized nodes into themes. Results: The interviewees relayed their experiences in the programme which includes provider non-adherence to accreditation pattern, poor reimbursement and tariff structure, fluctuations in prices of input, inadequate funding of the programme and low number of enrollees registered in private facilities and consequently proffered strategies on how to eliminate adverse selection and supplier induced demand with a resultant improvement in supply of health insurance services. Conclusions: Evidence from this qualitative study have shown various strategies if implemented will reduce the incidence of adverse selection and supplier induced demand which are mostly implicated as common causes of market failures.
\end{abstract}

Keywords: Supply of Health Insurance Services, Social Health Insurance Programme, Market Failure, Adverse Selection, Supplier Induced Demand

\section{Introduction}

The formal sector social health insurance programme being a means of achieving universal health coverage has five stakeholders (Regulators, HMOs, Providers, Payers and Enrollees) whom are important in the implementation of the programme in Nigeria [1-3]. However, the principal (user/enrollee) and agent (provider) relationship is key in the process of supply of quality and utilization of quality healthcare services [4]. The provider (agent) being an informed agent based on his/her professional knowledge at his/her disposal will therefore make informed choices for 
the principal (enrollee) [5-6]. In this principal - agent relationship, the principal believes that the agent have better knowledge than them. As the principal relinquishes decision making to the agent, the agent may make the principal consume more or less healthcare [7-8]. This situation is therefore known as supplier induced demand and it is mostly linked with fee-for-service payment system which provides a clear incentive linking service volume to profit [9-8].

A number of hypotheses have been adduced to explain supplier induced demand. One of them is the target income hypothesis which suggests that a provider will do everything possible to maintain a high income level but when this high income levels falls below the expected high income level; the provider will change his/her approach so as to restore the income to the expected high level [10]. Also, another hypothesis is the professional uncertainty hypothesis which tries to explain supplier induced demand. This theory suggests that in medical practice, provider practice pattern is autonomous (i.e differ from provider to provider). Similarly, provider practice pattern differences manifest in their opinion regarding what constitutes success of different treatment protocol for any particular condition. Due to this non uniformity in their practice pattern, it has led to different levels of demand from enrollees who are accessing health insurance services [11].

Another challenge in the principal agent relationship is adverse selection and this situation arises when patient form a pool with the intention of receiving health services from one healthcare provider and thereafter contributes equally into the pool [12]. Each member of the pool knows his probability of using health services from the doctor and equally knows that the price is set at an average cost and that the pool members with below average needs, subsidizes for those whose needs are above average. This situation therefore arises when those with below average needs opt out from the arrangement leaving only those with above average needs [13]. Another scenario is a situation where the healthcare providers chose to provide healthcare services to healthier enrollees and leaving out the enrollees with multiple health challenges by referring them out to other centres [13]. All these problems of supply side moral hazard and adverse selection arising mainly due to informational asymmetry will finally lead to market failure in the health insurance industry [13-14].

However, since the interaction between the providers and enrollees may result in supplier induced demand and adverse selection which invariably to a great extent will determine whether the market in the social health insurance programme will fail or not. Therefore, there is a need to look at new ways to improve the supply of health insurance services in order to combat incidences of supplier induced demand and adverse selection. Hence, the purpose of this study which is to deduce unique ways of improving the supply health insurance services in the social health insurance programme in Nigeria.

\section{Method}

\subsection{Study Area}

Enugu State was the study area and has an estimated population 3,257,298 million with a land mass of 7,618 km according to the last census figure. The state has boundaries with Imo and Abia states in the south, Ebonyi state in the east, Anambra state in the west while Kogi and Benue states in the north [15].

\subsection{Study Design}

A qualitative design with an in-depth interview component was adopted. The design is deemed appropriate for this study because it provided an opportunity for the respondents to extensively proffer new ways to improve supply of health insurance services in the social health insurance programme in the country.

\subsection{Sample Size/Instrument for Data Collection}

In-depth interview method was conducted to elicit information from each of the Chief Medical Directors of nine purposively selected hospitals (government owned hospitals (3), mission hospitals (3) and privately owned hospitals (3) on interventions that will improve supply of health insurance services to enrollees using a semi structured in-depth interview guide with probe questions [16].

\subsection{Validity of Instrument}

Face and content validity technique were utilized to validate the instrument. Ambiguous statements were removed and corrections made were used to modify final statements. In the content validation, the relevance of the items were evaluated using a rating scale

\subsection{Reliability of Instrument}

The focus group questions were pre-tested on group of respondents from selected Government owned, missionary and privately owned hospitals in Awka, Anambra state. A test retest method at interval of 2 weeks was done for the qualitative instruments and the responses were computed using Pearson product moment correlation coefficient formula. A coefficient reliability of 0.72 was obtained for the instrument and these therefore showed that the instrument was reliable.

\subsection{Procedure for Data Collection}

Nine In-depth interviews were conducted among the purposively selected Chief Medical Directors (CMDs) of NHIS accredited healthcare providers over two months (October-November 2018). The researcher sought appointments from the CMDs by phone calls and visits to each selected CMDs. The selected CMDs were interviewed in their various clinical offices. The aim of the study was fully explained to them. They were made to sign informed consent form, thereby authorizing their participation and 
audio recording of the interview. All the interviews with the participants were conducted in English, audiotaped and later transcription of the interview was done. Each of the interviews lasted between 30-45 minutes. After each interviews, audiotaped discussions were replayed to the participants.

\subsection{Qualitative Data Analysis}

This study adopted qualitative content analysis [17-18] and verbatim transcriptions of the audiotapes of in-depth interviews were prepared so as to capture the opinions of the respondents in their own words [19]. Inductive code development was achieved by reading through one in-depth interview transcript, and assigning appropriate codes to emerging themes [20]. Transcripts were imported into NVIVO 11 software (QSR International Pty LTD, 2015) after the removal of all personal identifiers. Eight Nodes or containers were created and initial analysis involved performing a similar word frequency which was depicted as a word cloud and later text search command was performed resulting in creation of word tree. All the significant information captured was housed inside container called nodes. In vivo coding method was used to code all the relevant information. Validation of the coding process was achieved with the assistance of an expert in qualitative analysis based at Medserve healthcare consulting services and consensus on the coding process was thereafter built. Based on similarities and relationships the codes were then categorized into big containers called parent codes. These big containers or themes were thereafter used to address the research topic.

\subsection{Ethical Consideration}

Ethics committee of Enugu state Ministry of Health approved the study. Each participant signed an informed consent form. Codes were used to identify each respondent in the study and similarly, personal and institutional identifiers were removed before the transcripts were imported into the NVIVO software so as to ensure anonymity.

\section{Result}

The themes for this in-depth interview were developed from the interviews conducted among purposely selected Chief Medical Directors of accredited healthcare providers (government-owned, mission-owned and privately-owned) in Enugu state. The themes were provider accreditation pattern, provider reimbursement structure, NHIS tariff structure, claims settlement, price of input and funding arrangement in the programme.

\section{Provider Accreditation Pattern}

The providers interviewed were well aware of the levels of accreditation pattern in Nigeria, "NHIS accredit providers for primary, secondary or tertiary care so as to ensure accessibility and availability of health insurance services to enrollees" (MD1, Mission).
Most of the providers interviewed stated that there is a high level of non-adherence to the levels of accreditation. Some primary cases that ordinarily will be handled at the primary level were referred to the secondary and tertiary level, and this may not be unconnected with the fact that most of the primary providers have few enrollees. A key informant captured it this way (MD2, Government).

"The primary care providers try to select the type of cases they see in order for them not to spend so much resources in the treatment of enrollee".

Most of the participants agreed that some cases that were referred by the primary providers were in the capitated list and the referral were done in connivance with HMO staff that statutorily authorize the treatment. According to them, this is an attempt to aid the primary providers with very few enrollees to avoid incurring cost in the course of treatment.

Also, it was revealed by the in-depth interview participants that tertiary institutions in the programme, who are usually government funded and supposed to be referral centers currently, handle primary cases and as a result enrollees choose them thereby leaving the primary providers with little or no enrollees. This invariably influences primary providers' service provision. A key informant referring to the number of enrollees the tertiary institutions have said (MD2, Private).

"I believe that if the tertiary institutions are excluded from handling primary cases.... the enrollees in the programme will choose us.... as a result most of us will have large pool of enrollees...... as a result we will have enough incentive to be in the programme and offer better services".

Another key informant on reporting to adherence to level of accreditation captured it this way (MD1, Government).

"If primary providers do not handle secondary and tertiary cases..... giving them services they do not require....... the level of mismanaged cases to me will be less and therefore enrollees will have more confidence in the programme".

Similarly, the participants unanimously agreed that strict monitoring and application of appropriate penalties to erring providers will help in reducing adverse selection and supplier induced demand in the programme. As said by a participant.

"If the law is followed judiciously, all these will definitely stop".

\section{Provider Reimbursement Structure}

All the participants have knowledge about the reimbursement structure in the programme, "Capitation payments are paid quarterly to providers while fee for service are paid fourteen days after submission of claims by the providers" (MD2, Mission). The participants revealed that most HMOs default in this regard and this greatly have hampered the service delivery to the enrollees. A key informant highlighted the effect late reimbursement of providers have on their operations in this quote (MD1, Private).

"Do you know that most of the HMOs are owing providers for six, seven, eight months..... please tell me how the providers can sustain rendering health insurance services to enrollees...... infact, some providers have stopped attending 
to NHIS enrollees...... the providers that treat them does so shabbly.... so if they want us to attend to them well, let them pay us on time".

Similarly, it emanated from the participants that some providers induce enrollees to accept services not really needed and this is in attempt to make more money in order to compensate for the delays in reimbursement. One of the participants captured it this way (MD1, Private).

"We will definitely find a way to get our money back since they have decided not to pay us on time".

The participants indicated that the rise in exchange rate have affected the price of consumables. One of the participants (MD1, Mission).

"There is an urgent need to always review the reimbursement to us because this will help us to meet up with our obligations to the enrollees...... if not, we will be referring the health insurance enrollees out to government hospitals...... and this will definitely have effect on the programme".

The participants unanimously agreed that timely payment of providers should be encouraged and NHIS officials should closely monitor the reimbursement of provider and sanction severely erring HMOs, so as to serve as a deterrent to others. Also, the participants agreed that frequent review of reimbursement structure should be operationalized. As captured by a participant (MD2, Government).

"I am telling you timely payment and frequent review of the reimbursement will serve as a motivation to the providers".

\section{NHIS Tariff Structure}

The participants identified NHIS tariff as the baseline prices of services which the HMOs now use for vetting the claims that the providers send to them. The participants stated that the prices of consumables have continuously been on the rise and providers were finding it difficult offering services to the enrollees in the programme at the same price for the past five years. A key informant postulated that it might be the reason providers induce enrollees to use more services and then captured it this way (MD2, Government).

"We have complained to NHIS on the need to frequently review the tariff structure so as to reflect the current economic realities.... the current tariff structure is not sustainable again considering the fact that exchange rate have been unstable..... at the end of the day, enrollees will not be attended to properly...... some of the providers have resorted to adding more services to the enrollees in order to make up the difference".

All the participants agreed that reviewing the NHIS tariff frequently to reflect the economic condition of the country will go a long way to influence treatment being given to enrollees. A key respondent put it succinctly (MD2, Mission).

"If the NHIS will be able to review the tariff structure frequently.... I think it will influence the quality and quantity of services the providers will be offering the enrollees and eventually will lead to improvement in the demand and supply of health insurance services".

Claims Settlement
Most of the participants stated that they submitted the details of services provided to each enrollee to the HMOs immediately after treating the enrollee and expected payment to be made fourteen days after the receipt of the claims. The participants reported being owed large sums of money by the HMOs because of them not giving attention to the submitted claims and as a result most of the health insurance enrollees were referred out to other hospitals and the ones that were treated, the services not really needed were added to them to compensate for the debt. As captured by one key informant (MD1, Private).

"Some of them owe us thousands of naira and as a result, we cannot sustain the treatment of enrollees in the programme".

Also, the participants noted that the HMOs take advantage of the fact that the claims submitted to them takes time to get to their respective head offices thereby claiming ignorance of the claims submitted by providers. As a result, submitted claims from providers pile up in their respective offices without being attended by them. As captured by a key informant (MD2, Private).

"We submitted this claims every month in their offices but I can tell you that they still owe us for many month".

The participants believe that such behaviours by HMOs has affected their operations because by the time they receive the payments, they may not be able to buy drugs and other consumables because their prices must have gone up so high. Also, this type of behaviour according to the participants occurs because of poor regulation by NHIS and it manifests in their inability to effectively control errant HMOs, some of whom are owned by influential members of the society. One of the respondents captured it aptly like this (MD2, Government).

"If the NHIS can do their job by properly regulating the activities of these HMOs and equally apply appropriate sanctions where necessary..... I think all these nonsense will stop and enrollees will be better off for it".

Furthermore, the participants advocated for the use of point of service (POS) based machine which will enable automatic transfer of claims to the HMOs and might invariably reduce response time and paperwork. Also, this will affect the prices they buy drugs and consumables because of availability of fund. As stated by a participants (MD1. Government).

"Let the regulatory body urgently introduce this machine if they want this problem of providers not treating health insurance patients and adding services not needed to them".

Price of Input

The participants adduced that it takes the HMOs a long time to pay for services rendered to their enrollees. According to them, this have really affected the number of NHIS enrollees they treat and has equally affected the type of drugs and services they render to these group of people. As captured by one of the participants (MD2, Private).

"I try not to manage the enrollees on the social health insurance..... but if I must ...... I usually add services so as to increase their bill..... I know that the payment will take 
time to come...... this will compensate for the time it will take to pay me".

Likewise, the participants unanimously agreed that they are not able to replace items used in treating the enrollees because of late payment for services rendered. In fact, some of the participants revealed that by the time the HMOs will pay them which usually take months, the prices of the items would have gone up so high that the money will not be enough to buy items to replace the used ones again. A participant captured it this way (MD1, Private).

"The money I received last week was for the services I rendered 5 months ago.... please tell me if the prices of things now is the same 5 months ago.... this is the issue we are talking about".

The participants noted that if the late payment for services rendered continues, the problem of selecting enrollees and adding services not required will get worse because the providers must remain in business or else they will close down. One of the participants said (MD2, Mission).

"In the past 6 months, about three providers have closed and I know many that have stopped seeing insurance patients".

The participants therefore advocated for frequent review of tariff structure in the programme so as to reflect the economic realities of the time. One of the participants captured it succinctly (MD2, Government).

"If the tariff is reviewed upwards often, I think, it will definitely take care of the constant fluctuations in the prices of drugs and other consumables".

Funding Arrangement in the Programme

The participants noted that the contributions are earningrelated where the employer contributes partly while the employee pays the other part. The participants stated that the funding in the programme is inadequate and it has impacted on the reimbursement and the tariff structure which will thereafter influence the providers to adversely select the enrollees to treat and add more services that are not needed to enrollees in order to maximize profit and also compensate for fewer enrollees in the programme. A key informant noted thus (MD1, Private).

"I believe that presence of more funding in the programme will definitely reach all the providers and make us not to select the enrollees to treat".

Another key informant also said (MD2, Private).

"The upward review of the reimbursement and tariff structure due to improved funding will definitely influence the providers provision of better and quality services to enrollees and thereafter improve demand and supply of health services".

The participants unanimously agreed that the funding of the programme can be improved upon by imposing taxes on luxury goods in the country, using revenues from VAT to fund the programme, making the programme mandatory for every citizen, exploring avenues to encourage donor agencies to fund the programme and encourage individual donation into the programme. A key informant (MD1, Private) captured it like this,
"If the programme is made mandatory with attendant more enrollees...... it will lead to more money being channeled into the programme from other sources....... I believe that the programme will be a huge success".

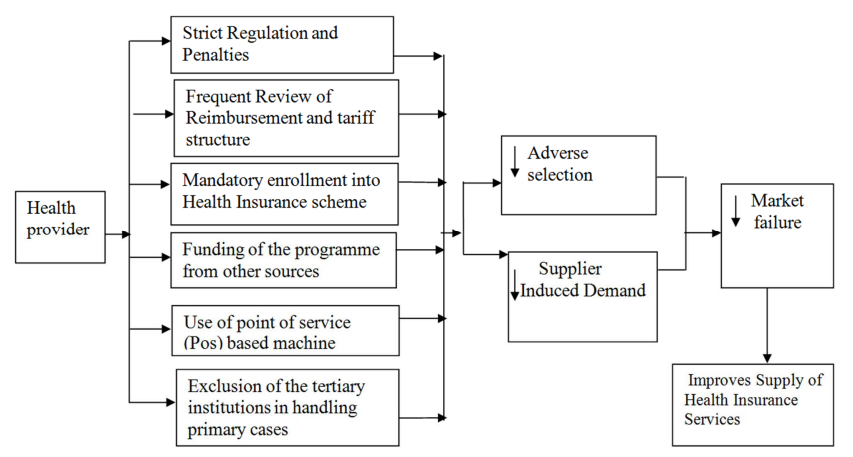

Figure 1. In-depth interview Participants' Proposed Interventions for Improving the Supply of Health Insurance Services as Conceptualized by the Researcher.

The conceptual framework was developed from the responses of the participants in the In-depth interview. In the conceptual framework, the participants concluded that in order to improve the supply of health insurance services in the social health insurance programme (SHIP), the two major causes of market failure in health insurance industry, which are adverse selection of enrollees by the health insurance providers and supplier induce demand must be eliminated or reduced. The following measures were advocated by the participants.

\section{Strict Regulation and Penalties}

The participants believes that if strict regulation of the activities of the HMOs and providers of services are performed by the regulatory body (NHIS), the issues of provider selectively referring enrollees to other centers will be reduced, timely reimbursing of the providers and timely settlement of claims, which have effect on the price of procuring inputs used in rendering services will be reduced. In addition, severely penalizing erring HMOs and providers will equally serve as a deterrent to others. This strict regulation and meting out appropriate penalties will drastically reduce both adverse selection and supplier induced demand which invariably will reduce market failure and finally improve supply of health insurance services.

Frequent Review of Reimbursement and Tariff Structure

Similarly, there is a need to frequently review the reimbursement and tariff structures in the programme so as to reflect the economic situation of the country. This upward review of the reimbursement and tariff structure will drastically eliminate adverse selection and supplier induced demand and thereafter reduces the incidence of market failure and the supply of health insurance will definitely improve.

\section{Mandatory Health Insurance}

It was the views of the participants that making social health insurance programme mandatory in the country will definitely increase the expectations of the provider which is having a large number of enrollees with attendant funds 
accruing (capitations) to the providers. This attendant fund (capitation) will go a long way in reducing the incidence of adverse selection and supplier induced demand and finally market failure will be on the decline and subsequently improvement in the supply of health insurance services.

Funding from other Sources

Also, the participants advocated for adequate funding of the programme in the country from VAT, donor agencies, voluntary donations from citizens and from taxes accruing from luxury goods. They believed that if the programme is adequately funded, it will increase the expectation of the providers with resultant reduction in adverse selection of enrollee and supplier induced demand, then market failure will be on the decline and subsequently there will be an improvement in the supply of health insurance service.

Exclusion of the Tertiary Hospitals from Handling Primary Cases

The views of the participants were that a lot of the enrollees choose the teaching hospitals as their primary care providers because of the fact that they have a lot of specialists. Equally, the teaching hospitals get subventions from the government. Hence, if the tertiary hospitals were excluded from handling primary care and become only referral centers, it will allow the primary care providers to have enrollees thereby increasing the number of enrollees in their facilities and thereby leading to elimination of adverse selection and supplier induced demand which will eventually result in reduction in market failure and finally improvement in supply of health insurance.

Point of Service (POS) Based Machine

This type of technology will help in reducing the amount of time it takes for the providers to prepare their claims and send it to the HMOs. Also, it will reduce the amount of time it will take the HMOs to work on the claims. As a result of the reduction in response time, the payment of the provider will be done on time resulting in the provider procuring the input used in rendering services to the enrollees at a reasonable price. Finally, it will lead to reduction in price of procuring input for service delivery and invariably will help in eliminating adverse selection and supplier induced demand and thereafter market failure and with subsequent improvement in the supply of services.

\section{Discussion}

Market failure is a condition that results when there are inefficiencies in the health insurance system thereby leading to its inability to meet up with its set out objectives. These objectives are absence of adverse selection and supplier induced demand which will result in provider supply of quality and efficient services to the consumers [13].

Market failures therefore can result from the type of provider reimbursement method which can be used as an incentive for providers to achieve the overall health system objective which involves reduction in the incidence of adverse selection and supplier induced demand. Consequently, the kind of payment incentive for healthcare providers will greatly determine supply of health service and subsequently reduction in the incidence of market failure [21-23].

In the in-depth interview result in this study, the respondents adduced that HMOs default in reimbursing them as and when due and they claim that this have hampered the supply of services to the enrollees. This is collaborated by the findings in the work of Dalinjong and Laar which showed that delays in reimbursing provider on time was significant in shaping their behavior in the health insurance programme and therefore have led to reported provider moral hazard behaviours in the programme [24].

Similarly, Ankomah in Ghana showed in his study that providers agreed that the fee for service was low and will definitely discourage a lot of providers from participating in the social health insurance programme [25]. The in-depth interview discussants therefore advocated for strict penalties for defaulting HMOs which tallies with the opinion of Onoka, Hanson and Mills [26] and frequent review of the reimbursement structure so as to accommodate the fluctuations in prices of input and this invariably will motivate the healthcare providers to deliver better services. The opinion of the respondents is supported by Cochran collaboration systemic review of 32 studies which concluded that financial incentives were significantly effective at improving the process of delivering healthcare services [27].

Also, the tariff structure was viewed as being very low by the providers and this might be the reason providers do not offer quality services to enrollees and equally refer health insurance enrollees to other facilities for treatment. This is consistent with the findings of Ankomah which also showed that tariff structure was low and providers in his study were not interested in treating health insurance patients in their study [25]. Consequently, the enrollee will seek for alternative healthcare service or pay out of pocket and this thereafter greatly impacts negatively on the demand for health insurance services. The in-depth interview respondents advocated for the need to frequently review NHIS tariff because of the perceived positive impact it will have on service delivery. This tally with a second Cochran review of incentives like pay-for-performance with the findings showing that frequent reviews of the tariff and reimbursement to primary care providers were found to have modest improvement in services delivered to patients [28].

Again, the respondents in the in-depth interview indicated in their responses that the delay in processing of their claims by the HMOs is the most important threat militating against their offering health insurance services to enrollees. The providers in this study reported being owed huge sums of money by the HMOs. This finding tally with the works of Onoka, Hanson and Mills in Nigeria and Ankomah in Ghana that showed majority of the respondents strongly agreed that their submitted claims processing time was long [26-25]. They advocated for the regulatory body applying appropriate sanctions where necessary to discourage this act and implore the National assembly who are the representative of the people and are supposed to be performing this mandatory oversight on the regulatory body to intensify effort in this 
regard.

Finally, the respondents in the in-depth interview reported poor funding/pooling of fund in the programme in the country which might be as a result of the programme not being mandatory for the citizens and has led to nonachievement of the universal health coverage. The findings in this study concurs with the work of Uzochukwu, Ughasoro, Etiaba, Okwuosa, Envuladu and Onwujekwe in Nigeria which showed that the funding of the programme in the country is poor and equally suggested ways on how to improve the funding which will invariably lead to efficiency in the supply of health insurance services [29]. Similarly, the respondents adduced that tertiary institutions in the programme who usually get government subvention and equally supposed to be referral centers, currently handle primary cases thereby depriving the private primary providers of the needed enrollees which would have resulted in them having enough fund. This scenario might have led to the primary private providers not supplying the needed services.

\section{Conclusion}

The findings in this study revealed the experiences of the in-depth interview participants and a conceptual framework for limiting the incidence of market failure resulting from adverse selection, supplier induced demand which includes strict monitoring and penalties, the use of POS-based machine, frequent review of the tariff and reimbursement structure, mandatory enrollment into the programme, limiting primary case management to private healthcare providers, funding of the programme from other sources was developed. The findings in this study will therefore serve as a guide, implementation tools, and reference documents to the Government of Nigeria and National Health Insurance Scheme (NHIS) while reviewing, formulating and implementing relevant strategies on how to improve the provider supply of health insurance services to the enrollees in the programme which eventually will reduce the incidence of adverse selection and supplier induced demand with attendant elimination of perceived market failures in the programme.

\section{References}

[1] Awosika, L. (2007). Health insurance and managed care in Nigeria. Ann Ibadan Postgrad Med. 3 (2), 40-51.

[2] Adibe, M. O., Udeogaranya, P. O. \& Ubaka, C. M. (2011). Awareness of national health insurance scheme activities among employees of a Nigerian university, Int. J. Drug Dev. \& Res. 3 (4): 78-85.

[3] Osungbade, K. O., Obembe, T. A., \& Oludoyi, A. (2014). Users Satisfaction with Service Provided under National Health Insurance Scheme in South Western Nigeria. International Journal of Tropical Disease and Health, 4 (5): 595-607.
[4] Gabel, J. (2008). Where do I send thee? Does physician ownership affect referral patterns to ambulatory surgery centers? Health Affairs, 27, 165-174.

[5] NHIS. (2015). National health insurance scheme operational guidelines. Abuja, Nigeria: National Health Insurance Scheme.

[6] Nguyen, H. (2011). The principal-agent problems in healthcare: evidence from prescribing patterns of private providers in Vietnam. Health Policy Plan, 26, 52-62.

[7] Arrow, K. (1963). Uncertainty and the welfare economics of medical care. American Economic Review, 53 (5), 941-973.

[8] Cromwell J., \& Mitchell, J. B. (1986). Physician-induced demand for surgery. Journal of Health Economics, 5, 293-313.

[9] McGuire, T. G. (2000). Physician agency. In Culyer, A. J \& Newhouse, J. P. (Eds). Handbook of Health Economics, (pp. 461-536). Amsterdam: Elsevier Science.

[10] Folland, S., Goodman, A. \& Stano, M. (2013). The economics of Health and Health care (7thed.). Boston, MA: Pearson.

[11] Weinberger, S (2011). Providing high value, cost conscious care: a critical seventh general competency for physicians. Annals of Internal Medicine, 155, 386-388.

[12] Stavropoulou, C. \& Glycopantis, D. (2009), The doctorpatient relationship under general conditions of uncertainty. Imperial Business School Discussion Paper Series, Discussion Paper No 2009/06. Access on 14/5/16 at http://www.ibs.org/documents/health/MrktStrOfHlthIns.pdf.

[13] Onwujekwe, O. E., Uzochukwu, B. S., Ezeoke, O. P., \& Uguru, N. P. (2011). Health insurance principles, models and the Nigeria national health insurance scheme. International Journal of Medicine and Health Development, 16, 1-3.

[14] Cheng, T. C., Haisken- DeNew, J \& Yong, Y. (2014). Cream Selection and hospital transfers in a mixed public-private system. Health Policy, 11 (1), 43-45.

[15] NPC. (2006). National census figures. Abuja, Nigeria: National Population Commission.

[16] Anderson, C. (2010). Presenting and evaluating qualitative research. American journal of pharm. Education, 74 (8), 141.

[17] Cho, J. Y. \& Lee, E. (2014). Reducing Confusion about Grounded Theory and Qualitative Content Analysis: Similarities and Differences. The Qualitative Report, 19 (32), 1-20.

[18] Creswell, J. W. (2007). Qualitative inquiry and research: choosing among the five traditions (2ned). Thousand oaks, CA: Sage Publications.

[19] Shreier, M. (2012). Qualitative content analysis in practice. Thousand Oaks, CA: Sage Publications.

[20] Boyatzis, R. E. (1998) Transforming qualitative information: Thematic analysis and code development. Thousand Oaks, CA: Sage Publications.

[21] Eggleston, K., \& Hsieh, C. R. (2004). Healthcare payment incentives: a comparative analysis of reforms in Taiwan, South Korea and China. Appl Health Econ Health Policy, 3 (1): 47-56.

[22] Robyn, P. J., Sauerborn, R., \& Baarnighausen, T. (2012). Provider payment in community-based health insurance schemes in developing countries: a systematic review. Health Policy and Planning, 28 (2): 111-122. 
[23] Alshreef, A. (2019). Provider payment mechanism: effective policy tools for achieving universal and sustainable healthcare coverage. Accessed on 7/10/2019 at https://www.intechopen.com/online-first/provider-paymentmechanism-effective-policy-tools-for-achieving-universaland-effective-healthcare-coverage.

[24] Dalinjong, P. A., \& Laar, A. S. (2012). The national health insurance scheme: perceptions and experiences of healthcare providers and clients in two districts of Ghana. Health Economic Review, 2, 13-16.

[25] Ankomah, M. (2009). Reforms in the provider tariff for the NHIS: Key implementation issues. NBER working paper series, 12 (3), 7206-7209.

[26] Onoka, C. A., Hanson, K., Mills, A. (2014). Growth of health maintenance organization in Nigeria and the potential for a role in promoting universal coverage efforts. Social Science and Medicine, 58, 70-74.

[27] Flodgren, G., Eccles, M., Shepperd, H., Scott, A., Pamelli, E. \& Beyer, F. (2011). An overview of reviews evaluating the effectiveness of financial incentives in changing healthcare professional behaviours and patient outcomes. International Journal of Science and Research, 38, 7.

[28] Eljkenaar, F., Emmert, M., Scheppard, M. \& Schoffski, O. (2013). Effects of pay for performance in healthcare: a systematic review. Health Policy, 110 (23), 150-80.

[29] Uzochukwu, B., Ughasoro, M. D. Etiaba, E., Okwuosa, C., Envuladu, E., \& Onwujekwe, O. E. (2015). Health care financing in Nigeria: implications for achieving universal health coverage. Niger J Clin Pract. 18, 437-44. 